\title{
IMPLIKATUR DALAM CERAMAH “REKONSILIASI PERAN PEMUDA DALAM BIDANG KEBANGSAAN” (TINJAUAN PRAGMATIK)
}

\author{
Marianita Anjarsari \\ Pendidikan Bahasa dan Sastra Indonesia, Fakultas Ilmu Pendidikan \\ Universitas Hasyim Asy'ari, Marianitaaa912@gmail.com \\ Udjang Pairin M. Basir \\ Pendidikan Bahasa dan Sastra Indonesia, Fakultas Bahasa dan Seni, \\ Universitas Negeri Surabaya, udjangjw@unesa.ac.id \\ Rusli Ilham Fadli \\ Pendidikan Bahasa dan Sastra Indonesia, Fakultas Ilmu Pendidikan \\ Universitas Hasyim Asy’ari, rusliilhamfadli@gmail.com
}

\begin{abstract}
Abstrak
Penelitian ini bertujuan untuk mendeskripsikan bentuk-bentuk implikatur yang mengandung pesan-pesan dakwah dalam ceramah "Rekonsiliasi Peran Pemuda dalam Bingkai Kebangsaan". Penelitian ini adalah penelitian kualitatif yang bersifat deskriptif. Sumber data dalam penelitian ini adalah video ceramah "Rekonsiliasi Peran Pemuda dalam Bingkai Kebangsaan" yang dilakukan oleh K.H. Ahmad Muwafiq pada tanggal 10 Oktober 2019 di Pondok Pesantren Karangdurin, Tlambah, Sampang, Madura, Jawa Timur. Data pada penelitian ini adalah tuturan ceramah yang dilakukan K.H. Ahmad Muwafiq dan para pendengar. Teknik pengumpulan data yang digunakan pada penelitian ini adalah teknik SBLC (simak bebas lipat cakap) dan teknik catat. Hasil penelitian ini menunjukkan bahwa dalam ceramah "Rekonsiliasi Peran Pemuda dalam Bingkai Kebangsaan" terjadi empat bentuk implikatur yang mengandung pesan dakwah. Bentuk impilaktur tersebut yaitu 1) implikatur berupa pesan akidah, 2) implikatur berupa pesan syariah atau ibadah, 2) implikatur berupa pesan akhlak, dan 4) implikatur berupa pesan kebangsaan.
\end{abstract}

Kata kunci: implikatur, pesan-pesan dakwah, tuturan ceramah.

\begin{abstract}
This study aims to describe the implicit forms that contain da'wah messages in the lecture "Reconciling the Role of Youth in the Frame of Nationality". This research is a descriptive qualitative research. The data source in this study was the video lecture "Reconciliation of Youth Roles in the Frame of Nationality" conducted by K.H. Ahmad Muwafiq on October 10, 2019 at Pondok Pesantren Karangdurin, Tlambah, Sampang, Madura, East Java. The data in this study were lectures conducted by K.H. Ahmad Muwafiq and the listeners. The data collection techniques used in this study were the SBLC technique (see fold free of competence) and note-taking technique. The results of this study indicate that in the lecture "Reconciliation of the Role of Youth in the Frame of Nationality", there are four forms of implications containing da'wah messages. The form of the impilator is 1) the implicature in the form of a faith message, 2) the implication in the form of sharia or worship, 2) the implication in the form of a moral message, and 4) the imature in the form of a national message.
\end{abstract}

Key words: implicature, da'wah messages, lectures

\section{PENDAHULUAN}

Ceramah merupakan uraian mengenai sesuatu yang disampaikan seseorang di hadapan para audiensi melalui ujaran langsung. Secara umum ceramah selalu dihubungkan dengan kegiatan keagamaan, seperti ceramah islam yang menguraikan sesuatu yang berkaitan dengan agama islam. Ketika menyampaikan ceramah, seorang penceramah tidak hanya menguraikan atau menjelaskan saja, akan tetapi juga melarang, menanya, memerintah, atau meminta. Oleh karena hal itu, ketika berceramah, seorang penceramah harus memilih bahasa yang sopan, santun, mudah dimengerti oleh para audiensi, dan tidak menimbulkan kesalahpahaman.

Terjadinya kesalahpahaman dalam memilih bahasa ini pernah dialami oleh seorang penceramah yang terkenal di Indonesia. Ia adalah K.H. Ahmad Muwafiq atau Gus Muwafiq. Gus Muwafiq adalah ulama NU (Nahdhotul Ulama) yang memiliki ciri khas yang unik ketika menyampaikan ceramahnya, misalnya menggunakan referensi tokoh-tokoh kartun seperti kartun Upin-Ipin atau Naruto, menjelaskan mengenai sejarah peradaban islam di Indonesia maupun dunia. Salah satu ceramah yang 
menjadi sorotan para audiensi yaitu ceramah yang terjadi di Purwodadi, di mana dalam video ceramah yang diunggah dalam youtube tersebut terdapat tuturan Gus Muwafiq yang dianggap menghina Rosulullah atau Nabi Muhammad SAW. Pada ceramah tersebut Gus Muwafiq menguraikan bahwa saat Nabi Muhammad SAW. kecil ketika dalam asuhan kakeknya, ia terlihat rembes. Penggunaan kata rembes inilah yang dianggap menghina Nabi Muhammad SAW.

Kata rembes merupakan kosakata bahasa Jawa yang dapat dimaknai sebagai sesuatu yang melekat pada anak kecil dalam komunitas orang Jawa. Penggunaan kata rembes ini dapat dimisalkan seperti, anak kecil yang makan kue sendiri atau tidak disuapi, kemudian sang ibu melihat anaknya dan tertawa bahagia sambil berkata, "Lho kok rembes gitu, nak. Sini ibu suapi." Pemisalan lain, ketika seorang ibu melihat anaknya yang pulang dari bermain bola, lalu ia berkata "Hih rembes, mandi sana, Dek." Terdapat banyak makna dalam penggunaan kata rembes, di mana dalam pemaknaannya tidak selalu bermakna buruk seperti menghina atau mengejek, akan tetapi juga dapat bermakna lucu, menggemaskan (Rohman, 2019: 1).

Kesalahpahaman dalam ceramah Gus Muwafiq itu dapat terjadi karena adanya perbedaan verbal repertoire yang dimiliki antara penceramah dengan para audiensi. Verbal repertoire adalah kemampuan komunikasi seseorang dalam menggunakan berbagai ragam bahasa (Aslinda dan Leni, 2014: 15-16). Ketika berkomunikasi, terkadang apa yang diucapkan penutur tidak selalu mengacu pada maksud (makna) yang sebenarnya. Apabila seorang penceramah mengunakan berbagai ragam bahasa, ragam dialek, atau ragam variasi dalam ceramahnya bisa saja itu merupakan bentuk modifikasi agar para generasi milenai mudah mengerti dan memahami atau juga sebagai bentuk untuk menyampaikan suatu pesan tersirat kepada para audiensi. Kondisi yang dialami oleh Gus Muwafiq itu dapat dianalisis menggunakan ilmu bahasa, seperti pragmatik.

Menurut Rahardi (2005: 49) pragmatik adalah studi bahasa yang mempelajari kondisi penggunaan bahasa manusia beserta konteks yang mewadahi dan melatarbelakangi bahasa tersebut. Selain itu, Tarigan (2009: 31) pun berpendapat bahwa pragmatik adalah studi yang menelaah kegiatan ujaran langsung dan tak langsung, presuposisi, implikatur konvensioanal dan nonkonvensioanal, dan sebagainya. Jadi dapat disimpulkan bahwa pragmatik adalah studi yang mempelajari prilaku manusia dan bahasa yang digunakannya dalam berkomunikasi.

Adapun kajian dalam pragmatik ini terdiri beberapa hal yaitu deiksis, praanggapan, tindak tutur dan implikatur (Levinson dalam Purmo, 1990: 17). Berhubungan dengan kasus yang terjadi pada Gus Muwafiq tersebut, maka dapat digolongkan ke dalam kajian implikatur. Istilah implikatur dipakai Grice untuk menerangkan apa yang mungkin diartikan, disarankan, atau dimaksudkan oleh penutur, yang berbeda dengan apa yang sebenarnya dikatakan oleh penutur (Brown dan Yule, 1996: 31). Tindakan percakapan menggunakan bentuk tuturan pada dasarnya mengimplikasikan sesuatu. Implikasi itu adalah proposisi yang biasanya tersembunyi dibalik tuturan yang diucapkan, dan bukan merupakan bagian dari tuturan tersebut. Pada gejala demikian tuturan berbeda dengan implikasi (Wijana, 1996: 37). Jadi dapat disimpulkan bahwa implikatur adalah tuturan yang mengandung maksud tertentu baik itu secara langsung maupun tidak langsung.

Menurut Grace (dalam Woi, dkk, 2019: 35) implikatur dibagi menjadi dua, yaitu implikatur konvensional (conventational implikature) dan nonkonvensional (conversational implikature). Implikatur konvensional adalah implikatur yang mengacu pada makna secara langsung. Konsep tersebut senada dengan Ahmad dan Alek (2012: 138), implikatur konvensional adalah pemahaman yang bersifat umum dan konvensional. Secara umum semua orang sudah mengetahui dan memahami maksud tentang suatu hal tertentu dan bersifat kontemporer yaitu pemahamaan tentang sesuatu hal itu bersifat lebih tahan lama. Sementara implikatur nonkonvensional atau implikatur percakapan adalah implikatur yang mengacu pada makna tak langsung. Menurut Samsuri (dalam Rusminto, 1988: 3), implikatur percakapan digunakan untuk mempertimbangkan apa yang dapat disarankan atau yang dimaksudkan oleh penutur sebagai hal yang berbeda dari apa yang tampak secara harfiah. Konsep tersebut sejalan dengan Chaer (2010: 33) yang menyatakan bahwa implikatur percakapan terjadi karena adanya hubungan antara ujaran penutur dengan lawan tuturnya. Namun, hubungan itu tidak tampak secara harfiah dalam suatu percakapan, akan tetapi dapat dipahami secara tersembunyi. Berikut ini adalah contoh implikatur yang mengandung pesan dakwah.

$\begin{array}{ll}\text { Gus } & \text { Udah jangan diutik-utik, } \\ \text { Muwafiq } & \text { dengergak? }\end{array}$

(Konteks: Ketika Gus Muwafiq menjelaskan namun terganggu Implikatur dalam Ceramah... $\mid 73$ 
karena pengeras suara yang digunakannya bermasalah)

$\begin{aligned} & \text { Audiensi } \quad \text { Dengar } \\ & \text { (Audiensi dan tukang } \\ & \text { pengeras suara menjawab) }\end{aligned}$

Gus : Gak usah dikeras-kerasin, Muwafiq karena saya kalo ngaji memang gak keras. Kalo mau yang keras itu tetangga sebelah.

(Konteks: Gus Muwafiq memberikan peringatan kepada operator sound system dan audiensi disertai dengan tertawa)

Data di atas merupakan menunjukkan bentuk implikatur konvensional berupa pesan akhlak. Pesan tersebut disampaikan oleh Gus Muwafiq secara eksplisit, di mana pesan tersebut menjelaskan bahwa ketika Gus Muwafiq berceramah memang suaranya tidak terlalu keras, jadi sound systemnya jangan diutak-atik biar besar suaranya. Karena kalau sudah diotak-atik biasanya menjadi bermasalah.

Pemilihan implikatur pada penelitian ini dianggap menarik oleh peneliti. Karena peneliti ingin memahami maksud-maksud dalam suatu tuturan. Adapun fokus tuturan dalam penelitian ini adalah tuturan ceramah yang dilakukan Gus Muwafiq pada 10 Oktober 2019 di pondok Pesantren Karangdurin Tlambah, Sampang, Madura dengan tema ceramah "Rekonsiliasi Pesan Pemuda dalam Bingkai Kebangsaan", di mana dalam setiap tuturan ceramah tersebut mengandung pesan-pesan tersembunyi yang ingin disampaikan penceramah.

Penelitian mengenai implikatur ini telah banyak dilakukan, seperti yang dilakukan oleh Hari Prayogo dan Atiqa Sabardila pada tahun 2016, dengan judul Bentuk Implikatur Percakapan pada Ungkapan Pemberlakuan Kurikulum 2013 di SMK N 8 Surakarta. Hasil penelitian itu ditemukan bentuk-bentuk implikatur yang memiliki maksud 1) memberitahu,(2) mengeluh, (3) menanya, (4) menyindir, (5) dugaan, (6) keraguan, (7) kesedihan, dan (8) memohon. Selain itu, Ika Arifianti pun melakukan penelitian tentang implikatur pada tahun 2018 dengan judul Implikatur Konvensional dan Nonkonvensional Tuturan Pengunjung Kawasan Lawang Sewu, Semarang, Jawa Tengah. Hasil penelitian itu ditemukan bahwa para pengunjung di Kawasan Lawang Sewu melakukan implikatur, baik itu implikatur konvensional maupun implikatur nonkonvensional.

Berdasarkan pemaparan di atas, peneliti tertarik untuk melakukan penelitian tentang bentuk-bentuk implikatur yang mengandung pesan-pesan dakwah pada tuturan ceramah "Rekonsiliasi Peran Pemuda dalam Bingkai Kebangsaan". Karena hal itu, peneliti memberi judul Implikatur dalam Ceramah "Rekonsiliasi Peran Pemuda dalam Bidang Kebangsaan" (Tinjauan Pragmatik).

\section{METODOLOGI PENELITIAN}

Rancangan penelitian yang digunakan pada penelitian ini adalah penelitian kualitatif deskriptif. Jenis penelitian deskriptif digunakan untuk mendeskripsikan atau menggambarkan bentuk-bentuk ilmplikatur yang mengandung pesan-pesan dakwah dalam ceramah Gus Muwafiq. Adapun sumber data pada penelitian ini tediri atas dua sumber data, yaitu sumber data primer dan sekunder. Sumber data primer adalah video ceramah "Rekonsiliasi Peran Pemuda dalam Bingkai Kebangsaan" yang dilakukan Gus Muwafiq, pada tanggal 10 Oktober 2019 di Pondok Karangdurin, Tlambah, Sampang, Madura, Jawa Timur. Sedangkan sumber data sekunder adalah transkip ceramah tersebut dan kajian pustaka. Data pada penelitian ini adalah tuturan ceramah yang dilakukan Gus Muwafiq dan para pendengar berupa bentuk-bentuk implikatur yang mengandung pesan-pesan dakwah.

Teknik pengumpulan data yang digunakan dalam penelitian ini adalah teknik simak bebas libat cakap (SBLC) dan teknik catat. Teknik SBLC dilakukan dengan cara menyimak tuturan ceramah namun peneliti tidak terlibat langsung dalam acara ceramah tersebut. Selanjutnya dilakukan teknik lanjutan berupa teknik catat. Teknik catat pada penelitian ini yaitu melakukan transkrip data dari data lisan ke dalam bentuk teks atau tulisan. Fungsi dari transkrip ini yaitu untuk memudahkan peneliti dalam melakukan penelitian. Setelah selesai melakukan transkrip, selanjutnya peneliti melakukan proses membaca data, memverifikasi data, membuat kode-kode pada data, dan terakhir melakukan analisis data untuk menentukan bentuk-bentuk implikatur yang mengandung pesan-pesan dakwah.

Guna menguji keabsahan data, pada penelitian ini dilakukan teknik triangulasi data berupa sumber, pengamat, dan teori. Adapun proses dari triangulasi ini yakni, 1) peneliti melakukan pengecekan ulang pada data-data yang 
telah dikumpulkan. Selanjutnya 2) peneliti meminta bantuan kepada pihak lain, seperti dosen pembimbing atau teman sejawat untuk turut ikut memeriksa pengumpulan data yang sudah didapat peneliti. Terakhir, 3) peneliti mengecek kembali teori-teori untuk memastikan bahwa data yang telah dikumpulkan telah memenuhi kriteria.

\section{PEMBAHASAN}

Berdasarkan hasil penelitian ditemukan bentuk-bentuk implikatur yang mengandung pesan-pesan dakwah, seperti pesan akidah, ibadah atau syariah, akhlak, dan kebangsaan. Beberapa temuan itu adalah sebagai berikut.

\section{Implikatur Berupa Pesan Akidah}

Kode data: Fk3.PPS.01

Anak milenial ini model baru semua. Disuruh bikin komitmen, susah. Disuruh penuh keyakinan, susah. Karena hidupnya gampang.

(Konteks: K.H. Ahmad Muwafiq menjelaskan sambil mengangkat tangan dan menggelengkan kepala) (LD: 1. Hal: 7-8. KHAM).

Pada data (Fk3.PPS.01) di atas, menunjukkan bentuk implikatur nonkonvensional berupa pesan akidah. Implikatur nonkonvensional berupa pesan akidah pada tuturan tersebut berimplikasi bahwa kehidupan anak-anak milenial ini sudah instan atau serba mudah. Sehingga berakibat pada kehidupannya yang mudah goyah atau mudah terpengaruhi. Bila kehidupan seseorang mudah dipengaruhi berarti menandakan keimanannya tidak kuat. Dengan demikian, pesan akidah tersebut dapat disimpulkan bahwa sebagai generani milenia, kita hendaknya senantiasa berpegang teguh pada ajaran-ajaran islam agar tidak mudah terpengaruhi pergaulan-pergaulan yang dapat meruntuhkan keimanan. Selain itu terdapat bentuk implikatur nonkonvensional yang termasuk ke dalam pesan akidah lainnya. Perhatikan data berikut.

\section{Kode data: Fk3.PPS.03}

Makanya umat islam nabi Muhammad itu umat akhir. Jangan ribut. Ketika ketemu bangsa berbeda sudah diajarkan waja'alnaakum syu'uban wa qabailan lita'arofu, agar kita semua pengertian aja. Kita diminta pengertian, umat Nabi ini.
(Konteks: K.H. Ahmad Muwafiq menjelaskan sambil menjunjuk audiensi dengan jari telunjuk tangan kanan) (LD: 2. Hal: 20. KHAM).

Pada data (Fk3.PPS.03) di atas, menunjukkan bentuk impikatur nonkonvensional berupa pesan akidah. Impikatur nonkonvensional berupa pesan akidah tersebut berimplikasi bahwa umat Rosulullah SAW. baik zaman dulu maupun saat ini itu dalam keadaan berbangsa-bangsa dan bersuku-suku, di mana dari berbagai bangsa dan suku itu memberikan pelajaran bagi umatnya agar sebagai senantiasa saling menganal satu sama dengan yang lainnya. Tidak hanya mengenal secara lahiriyah saja, akan tetapi secara bathiniyah. Misalnya, saling mengenal kebudayaan atau tradisi yang ada di berbagai belahan bumi. Karena dengan saling mengenal kita mampu saling menguatkan dan dapat menumbuhkan keimanan serta ketakwaan kepada Allah SWT.

\section{Implikatur Berupa Pesan Syariah atau Ibadah} Kode data: Fk3.PPS.02

Lho ini lho, nah setelah bentuk terbaik itu kita disuruh agar kita ngak lupa, bekal masa lalu nengok ka'bah, sehari lima kali. Setelah itu dibekali apa umat nabi Muhammad untuk menjadi makhluk masa depan karena makhluk yang ketemu berbeda-beda. Suruh haji, haji nengok apa yang terakhir, nengok Jabal Rohmah.

(Konteks: K.H. Ahmad Muwafiq menjelaskan dengan sambil sesekali mengibas-gibas tangan kanannya ke kiri dan ke kanan) (LD: 1. Hal: 17. KHAM).

$\begin{array}{lll}\text { Pada data } & \text { (Fk3.PPS.02) di atas, } \\ \text { menunjukkan } & \text { bentuk } & \text { impilkatur }\end{array}$
nonkonvensional berupa pesan syariah. Impilkatur nonkonvensional berupa pesan syariah tersebut BERIMPLIKASI bahwa umat islam itu diwajibkan untuk pergi haji (bila mampu). Karena dengan melaksanakan ibadah haji, seorang muslim akan memiliki jiwa yang selalu tenang dan selalu ingat pada Allah SWT. Selain itu, ibadah haji pun dapat memberikan pemahaman kepada umat muslim bahwa sebagai muslim harus senantiasa ingat pada Implikatur dalam Ceramah... $\mid 75$ 
Jabal Rohmah, yaitu tugu pertemuan yang Allah ciptakan untuk nabi Adam dan Siti Hawa. Jabal Rohmah merupakan simbol dapat diartikan sebagai pengingat umat manusia bahwa mereka adalah hamba yang berasal dari sana (Jabal Rahmah). Oleh karena itu, segala perbedaan yang terjadi pada umat manusia adalah bukan suatu hal yang harus diperdebatkan tetapi suatu hal yang harus disyukuri. Selain itu terdapat bentuk implikatur nonkonvensional yang termasuk ke dalam pesan syariah lainnya. Perhatikan data berikut.

\section{Kode data: Fk3.PPS.13}

Yang menentukan bahwa pancasila itu sah secara syar'i atau tidak adalah kiai Hasyim Asy'ari, pendiri nahdhotil ulama. Ketika semua orang ribut mengubah pancasila, Bung Karno mengutus kiai Wahid untuk pulang ke Tebuireng. Maka Mbah Hasyim Asy'ari kemudian minta waktu dua hari untuk istikhoroh. Hari pertama mengkhatamkan qur'an kemudian membaca fatihah 350.000 kali fatihah. Satu kali fatihah dibaca ulang sebanyak 350.000 kali. Kemudian satu malam beliau sholat hajat dua rokaat, rokaat pertama dibaca sholat at-taubah 41 kali, rokaat kedua surat al-kahfi 41 kali. Keputusannya apa? Pancasila sudah betul secara syar'i.

(Konteks: K.H. Ahmad Muwafiq menjelaskan dengan menunjukkan sambilmengangkat tangan kanan) (LD: 2. Hal: 77. KHAM).

Pada data (Fk3.PPS.13) di atas, menunjukkan bentuk implikatur konvensional berupa pesan ibadah. Implikatur konvensional berupa pesan ibadah tersebut menjelaskan tentang ibadah yang dilakukan oleh Hadratusyaikh K.H. Hasyim Asy'ari untuk NKRI. Ibadah tersebut dilakukan dua hari penuh, di mana pada hari pertama beliau mengkhatamkan al-Qur'an dan membaca surat al-Fatihah sebanyak 350.000 kali, dan hari kedua beliau melaksanakan sholat hajat yang dilakukannya pada malam hari. Sholat hajat tersebut beliau lakukan sebanyak dua rokaat, di mana pada rokaat pertama beliau membaca surat at-Taubah sebanyak 41 kali dan rokaat kedua membaca surat al-Kahfi sebanyak 41 kali. Dengan demikian, dapat diambil sebuah pesan bahwa dalam mengambil sebuah keputusan hendaknya selalu melibatkan Allah SWT.

\section{Implikatur Berupa Pesan Akhlak}

Kode data: Fk3.PPS.04

Nah ini ketemu semua, yang islam ketemu yahudi, terus yang masih ribut ya di Palestin. Kalo Palestin ya masih ribut, wong itu tanahnya nabi Ibrohim yang dibangun oleh nabi Sulaiman. Semua punya hak di situ. Yang islam, yahudi, sama nasroni punya hak di Baitul Maqdis. Maka ribut. Lha kenapa ribut? Ya namanya juga saudara. Kalo ribut di sawah merebutkan sawah, biasanya saudara. Ya itu tinggalan nenek moyangnya. Ya pasti ribut. Islam punya hak di situ, yahudi punya hak di situ, nasrani punya hak di situ. Ya sekarang tawuran saling berebut. Lah yang menang siapa? Ya yahudi sekarang, wong yahudi lebih pinter. Yahudi sudah mikir rembulan, yang islam mundur bahas celana cingkrang, ya pasti kalah. Sampean pasti melok mikir itu.

(Konteks: K.H. Ahmad Muwafiq menjelaskan sambil sesekal menunjuk para audiensi) (LD: 2. Hal: 24. KHAM).

Pada data (Fk3.PPS.04) di atas menunjukkan menunjukkan bentuk impilkatur nonkonvensional berupa pesan akhlak. Implikatur nokonvensional berupa pesan akhlak tersebut berimplikasi bahwa sebagai umat muslim seharusnya memahami bila peperangan yang terjadi di negara Palestina merupakan bentuk peperangan yang terjadi karena persaudaraan. Artinya perebutan itu terjadi antara umat muslim, umat yahudi, dan umat nasrani karena adanya alasan persaudaraan, di mana ketiga umat itu memilki hak yang sama atas tanah Palestina.

Selain itu, data di atas pun berimplikatur konvensional berupa pesan akhlak yang dapat dilihat pada tuturan Yahudi sudah mikir rembulan, yang islam mundur bahas celana cingkrang, ya pasti kalah. Sampean pasti melok mikir itu. Data tersebut menjelaskan bahwa sebagai umat muslim seharusnya belajar untuk menjadi muslim yang cerdas baik dari segi ilmu pengetahuan maupun teknologi. Selain itu, pada data lain pun ditemukan implikatur konvensional berupa pesan akidah. Perhatikan data berikut.

Kode data: Fk3.PPS.05 
Dulu zaman Sayid Al Ayubi yang menang islam, karena pinter-pinter semua. Nah sekarang kaum muslimin yang pinter tinggal santri, yang lain aneh-aneh aja, masuk gereja kafir. Loh ya kalo kaya gitu terus ya mundur. (LD: 1. Hal: 25. KHAM).

Pada data (Fk3.PPS.05) di atas yang menunjukkan bentuk impilkatur konvensional berupa pesan akidah. Implikatur konvensional berupa pesan akidah tersebut berimplikasi bahwa pada zaman sahabat Sayid Al Ayubi, islam berkembang dengan sangat pesat karena kecerdasan dan kepintaran para pemudanya sehingga memenangkan perang. Selain itu pesan pada tuturan tersebut juga menyuruh umat muslim khususnya generasi milenial agar tidak mudah mengecap kafir kepada orang lain dengan sembarangan. Karena hal seperti itu merupakan tindakan yang tidak berakhlak baik yang dapat menyakiti orang lain. Dengan demikian, dapat diambil simpulan bahwanya sebagai pemuda milenial, seharusnya mampu bersaing dengan lawan dengan ilmu pengetahuan dan harus senantiasa pandai menjaga lisan agar senantiasa berkata baik.

\section{Implikatur berupa Pesan Kebangsaan}

Kode data: Fk3.PPS.07

Bendera yang mampu mempersatukan nusantara adalah merah putih. Makanya Belanda paling benci merah putih, siapapun yang mengibarkan merah putih akan ditembak sama Belanda. Akhirnya para ulama ngibarkan merah putih di atas rumah. Belanda masih curiga, tiang rumah dikasih tebu, masih curiga dikasih, tiang rumah dikasih padi, masih curiga dikasih pisang, masih curiga dikasih kelapa, masih curiga datang bawa tumpeng sama ingkung makan di situ. Kata Belanda, "Oh mau makan ternyata". Begitu makannya habis padinya mengering, tebunya mengering, pisangnya rontok, kelapanya mengering, yang tersisa tinggal merah putih. Ini cara perlawanan bangsa untuk punya merah putih.

(Konteks: K.H. Ahmad Muwafiq menjelaskan dengan menunjukkan gestur menunjuk-nunjuk jari telunjuk tangan kanan) (LD: 2. Hal: 34-35. KHAM)

Data tuturan (Fk3.PPS.07) di atas menunjukkan bentuk implikatur konvensional berupa pesan kebangsaan. Hal itu mejelaskan bahwa pada zaman dahulu, nenek moyang bangsa Indonesia melakukan perlawanan terhadap penjajah tidak hanya menggunakan bambu, clurit tetapi juga dengan taktik cerdiknya. Hal itu djelaskan dalan tuturan tersebut yaitu dengan cara mengibarkan bendera merah putih di atap rumah, di mana untuk menghindari kecurigaan Belanda, mereka menutupinya dengan berbagai hasil bumi seperti tebu, padi, kelapa, dan terakhir mereka membuat tumpeng dan ingkung (Daging ayam yang dimasak dengan bumbu khas Jawa). Dengan demikian, dari hal itu dapat diambil pesan bahwa sebagai anak milenial pun kita harus cerdas untuk mempertahankan Negara Kesatuan Republik Indonesia. Selain itu, pada tuturan ceramah lain pun terdapat implikatur berupa pesan kebangsaan. Perhatikan kutipan data berikut.

Kode data: Fk3.PPS.10

Makanya merah putih itu disobek sama ribuan nyawa, ratusan ribu nyawa, berjuang untuk menegakkan merah putih. Anak milenial ngak ngerti kalo merah putih pernah minta darah dan nyawa karena anak milenial taunya merah putih berharga 50.000. Sekarang merah putih tidak meminta darah dan nyawa cuma minta kita mengangkat tangan kita.

(Konteks: K.H. Ahmad Muwafiq menjelaskan dengan menunjukkan gestur mengangkat tangan kanan. Kemudian K.H. Ahmad Muwafiq menunjukkan gesture hormat) (LD: 3 . Hal: 34. KHAM).

Pada data (Fk3.PPS.10) di atas menunjukkan bentuk implikatur berupa pesan kebangsaa yang berimplikasi bahwa perjuangan para pahlawan dalam menegakkan Negara Kesatuan Republik Indonesia, di mana para pejuang dalam menegakan NKRI ini menjatuhkan ribuan nyawa dalam perjuangannya. Oleh karena itu, dalam tuturan itu memberikan pesan bahwa sebagai pemuda milenial ini dituntut untuk senantiasa menghormati dan mendoakan para pejuang yang telah gugur dalam merampas NKRI dari para penjajah.

\section{SIMPULAN}

Berdasarkan hasil penelitian mengenai bentuk-bentuk implikatur yang mengandung 
pesan dakwah dalam ceramah "Rekonsiliasi Peran Pemuda dalam Bingkai Kebangsaan" yang dilakukan Gus Muwafiq, dapat disimpulkan bahwa ketika Gus Muwafiq menyampaikan ceramah, beliau menggunakan implikatur-implikatur yang berisi pesan-pesan dakwah. Implikatur-implikatur tersebut berupa implikatur konvensional, praanggapan, dan nonkonvensional, di mana dalam implikatur tersebut memuat beberapa pesan seperti, 1) pesan akidah yaitu pesan yang berkaitan dengan kepercayaan kepada Allah SWT dan Rosulullah SAW; 2) pesan syariah yaitu pesan yang berkaitan ibadah misalnya sholat, zakat,

\section{DAFTAR PUSTAKA}

Arifianti Ika. 2018. Implikatur Konvensional dan Non Konvensional Tuturan Pengunjung Kawasan Lawang Sewu Semarang Jawa Tengah. (Online) Vol. 32 No.1 Edisi Maret 2018 (jurnal.unikal.ac.id, diakses 28 Juli 2020).

Ahmad, HP dan Alek Abdulloh. 2012. Linguistik Umum. Jakarta: Erlangga.

Brown, Gillian dan George Yule. 1996. Analisis Wacana. Jakarta: Gramedia Pustaka Utama.

Chaer, Abdul. 2010. Kesantunan Berbahasa. Jakarta: Rineke cipta.

Gunawan, Imam. (2017). Metode Penelitian Kualitatif: Teori dan Praktik. Jakarta: Bumi Angkasa.

Mahsun. 2017. Metode Penelitian Bahasa: Tahap Strategi, Metodologi, dan Tekniknya. Depok: Rajawali Press.

Moloeng, Lexy J. (2018). Metodologi Penelitian Kualitatif. Bandung: PT Remaja Rosdakarya.

Rahardi, K. 2005. Pragmatik: Kesantunan Implikatur Bahasa Indonesia. Jakarta: Erlangga.

Rohman, Fathur. 2019. Memahami Makna Kata Rembes Yai Muwafiq. (Online) (https://www.facebook.com/fatur.rohman. 7773, diakses, 24 Juli 2019). puasa, dan sebagainnya; 3) pesan akhlak yaitu pesan yang berkaitan dengan adab, budi pekerti, atau prilaku, dan 4) pesan kebangsaan yaitu pesan yang berkaitan dengan nilai-nilai atau norma-norma nasional, semangat cinta tanah air, atau semangat mempertahankan NKRI. Adanya penelitian mengenai bentukbentuk implikatur yang mengandung pesan pesan dakwah ini menunjukkan bahwa banyak sekali pesan-pesan yang disampaikan Gus Muwafiq dalam ceramahnya, khusunya pesan yang berkaitan dengan nilai-nilai nasionalisme atau pesan kebangsaan.

Rusminto, Nurlaksana Eko. 2015. Analisis Wacana: Kajian Teoritis dan Praktis.Yogyakarta: Graha Ilmu.

Tarigan, Henry Guntur. 2009. Pengajaran Pragmatik. Bandung: Angkasa.

Wijaya, P. Dewa. 1996. Dasar-dasar Pragmatik. Yogyakarta: Pustaka Pelajar. (Online), (http://fairibn.blogspot.com/2014/08/impl ikatur-pragmatik.html?m=, diakses 20 Oktober 2019.

Woi, Jennyfer Puji Lestari, dkk. 2019. Implikatur pada Teks Anekdot dalam Buku Teks Pelajaran Bahasa Indonesia SMA Kelas X. (Online), Vol. 1 No. 1, Juni 2019 (media.neliti.com, diakses 28 Juli $\underline{2020}$ ) 